\title{
Entrevista a Juan Pablo Meneses
}

\author{
Eugenia Destefanis, Gigliola Foco, Juan Brodsky, \\ Juan Pablo Duarte, María Eugenia Castro
}

Juan Pablo Meneses es un cronista, escritor y periodista chileno que fundó lo que en la actualidad se conoce como "Periodismo Portátil". Sus crónicas del consumismo presentan una nueva forma del periodismo narrativo que toma como eje la experiencia de comprar. Desde su proyecto "Escuela de Periodismo Portátil"-que cuenta con alumnos conectados desde más de veinte países- Meneses descubre y promueve diferentes voces de la narrativa y el periodismo desde soportes experimentales e independientes.

Escribió los libros Equipaje de mano (Planeta 2003); Sexo y poder (Planeta 2004); La vida de una vaca (Planeta/Seix Barral 2008, finalista Premio Crónicas Seix Barral); Crónicas Argentinas (Norma 2009), Hotel España (Norma 2009 / Iberoamericana / Vervuert 2010) y Niños futbolistas (2013).

Actualmente, se encuentra trabajando en el último tomo de su trilogía de "periodismo cash", para el que compró un Dios en la India y fundó una religión en Nueva York con el objetivo de escribir un libro acerca de este tema. Inspirada en una serie de interrogantes que, en el marco de la teoría psicoanalítica lacaniana, podrían agruparse en torno a la noción de discurso capitalista, la presente entrevista aborda algunos aspectos de esta experiencia.

1) Muchas religiones se construyeron a partir de un libro. El Corán, el Bhagavad Gita, el Popol Vuh, La Torá. Los Evangelios constituyen un caso especial, existen cuatro versiones canónicas, cuatro formas de contar la misma historia. Sin embargo, usted optó por tomar la dirección opuesta, comprar un dios para escribir un libro ¿Por qué? ¿Qué lugar considera que ocupa la idea de Dios en la vida de la personas?

J.P.M: Siempre me ha interesado la idea de construcción de cultura y de sociedad a partir de libros. Ahora mismo, muchos critican la falta de importancia de los libros, pero crecen los movimientos religiosos que avanzan con un libro en la mano, turbas que quieren cambiar el mundo en nombre de un libro. No importa si es la Biblia, en el caso de los populismos de la derecha latinoamericana, o el Corán adoptado por el fanatismo musulmán. Hoy tenemos movimientos que crecen, que quieren infiltrarse en nuestra vida diaria, mover todo, y lo hacen a partir de libros. Eso es muy literario, aunque siento que el mundo de los libros no le da importancia o no asume la responsabilidad del asunto.

Por eso me gusta la idea de hacer camino inverso, con este proyecto. Es decir, comprar un dios y armar una religión, que se terminará cuando yo publique este libro. Me gusta estar trabajando con la relación entre libro y religión en directo, en vivo, contando el proyecto. Este libro ya existe, antes de ser publicado, y publicarlo sólo será la parte accesoria del plan. Hay un capitulo del libro, donde está detallado el viaje en que me tocó vivir un momento único de esta relación libro-religión. Fue en la India. Viajé a Amritsar, me hospedé en la ciudad sagrada de los Sij, y al día siguiente hice la larga fila del Templo Dorado. Adentro está el Sri Gurú GranthSahib, el libro sagrado de los sij. Está ahí, un original. Tapado con mantas, un maestro sij le tira viento con un abanico al libro, lo cuidan y mantienen muy devotamente.

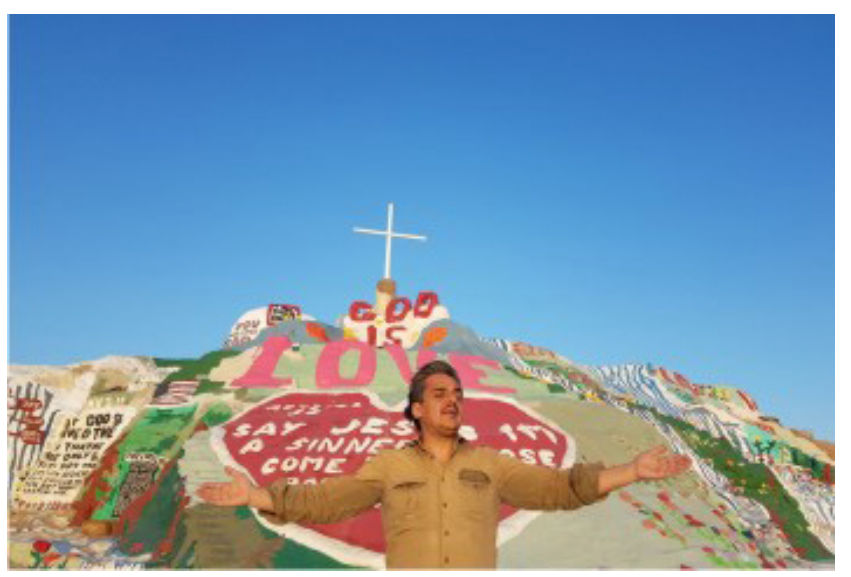

Por lo mismo, decir un lugar sagrado que ocupe Dios, es imposible. Hay muchos. Cuando Bolsonaro fue elegido presidente de Brasil agradeció a dios 
y dijo que gobernaría con Dios al lado de la Constitución de su país. Yo le pregunté, vía twitter, que de cuál de todos los dioses iba a gobernar, porque con el mío, con el que compré en la India, no lo iba a hacer.

2) El 4 de Julio de 2014, el mundial de fútbol de Brasil, Wimbledon, el Tour de France captaban la atención del mundo y en Estados Unidos se celebraba el Día de la Independencia. Mientras tanto, en Mosul alguien se proclamaba sucesor de Mahoma y fundaba el Califato entre las burlas y el sarcasmo de grandes medios de comunicación. El consumo de masas tiene que ver también con la fecha en la que usted lanza la religión portátil ¿̨Por qué elige de lanzar la religión portátil el mismo día que el Black Friday? ¿Su experiencia de investigación periodística le ha permitido reflexionar acerca del fanatismo religioso en nuestra época?

J.P.M: Las fechas son importantes, especialmente para los medios de comunicación. Hace que todo sea más fácil de explicar, de transmitir. Los medios necesitan contar las mismas efemérides de siempre, de todos los años repetidos, pero de una manera diferente. Cuando yo anuncié en mis redes sociales que lanzaría una religión un 24 de noviembre, para Black Friday, lo elegí pensando que ese día es la fiesta del consumo y que la compra de mi dios es parte de un libro, que conforma una trilogía del consumo. En ese tiempo estaba viviendo en Nueva York, y escuchaba muchas historias exageradas de clientes aplastados por la turba de compradores. Gente esperando días afuera de una tienda, para atrapar una oferta inigualable. Los días previos es un bombardeo absoluto de esa paranoia, de esa religiosidad consumista. Y los medios de comunicación son parte de la juguera. O lo incentivan más. No hay que ser un fanático de la Escuela de Frankfurt para entender que todo es parte del mismo guiso de la comunicación social. Y así fue que no pasaron muchas horas de que publiqué en mis redes que lanzaría mi religión en Black Friday, y me escribió un periodista de los diarios Metro, los diarios que se entregan gratis en muchos países. Le habían encargado una nota de Black Friday y él, aburrido de repetir lo clásico, quería hacerla con algo distinto: Y mi religión, lanzada un Viernes Negro, le calzaba perfecto. Hicimos la entrevista, y salió publicada el día previo, en varios países. Y, de paso, terminó alertando a alguna gente que llegó al lanzamiento de sorpresa.
Todo el segundo semestre del 2017 estuve viviendo en Manhattan, con una oficina en la New York University (NYU), y ahí afiné todos los detalles de la religión. Estaba en Nueva York como Visiting Scholar del Centro de Religión y Medios de NYU, un departamento fascinante donde se estudia toda la relación mediática de las religiones y de los fenómenos religiosos con los medios. El fanatismo religioso tiene una relación muy directa con la Comunicación, pero no son un invento de los Medios. Es cierto lo que dicen, que muchos Medios se reían y mofaban de los autoproclamados Mahoma, Dios, y hasta de las candidaturas como la de Trump. Yo estaba en Stanford para la campaña presidencial de Trump, y en cada debate con Hillary nos juntábamos en un gran salón, con pizzas y cervezas, para reírnos y hacer mofa de las declaraciones de Trump. Era una elite intelectual burlándose de alguien que terminó siendo presidente y que nadie supo ver de otra manera que con burla. Lo mismo pasa con los fanatismos religiosos. Lo mismo está pasando ahora, mientras escribo este libro.

3) Su trilogía permite hacer cierta crónica del consumismo. En "La vida de una vaca" lo presenta comprando un animal y en "Niños futbolistas", un niño y ahora un Dios. Asimismo, refiere a que el primer interesado en este último proyecto fue un corredor de bolsa, entonces: ¿Es posible separar consumo de experiencia en la actualidad? ¿Qué nos podría decir acerca de la relación entre la religión portátil y el mercado? ¿El Dios que usted compra puede pensarse como un objeto de consumo?

J.P.M: Me gusta explorar nuevas herramientas literarias para la no-ficción, correr los límites para investigar, para reportear, para estructurar una historia. No aburrirme. Esta misma entrevista, seguramente, será parte del libro. Pero no fue respondida para el libro, o tal vez sí. Yo mismo no sé si estoy respondiendo esta entrevista para ustedes, o para mi libro. Todo ese cruce, me entusiasma creativamente. Me interesa esta manera de ir construyendo un relato por medio de distintas entrevistas, a partir de un libro que no se ha publicado, pero que se publicará, y que estará compuesto por esas mismas entrevistas. Pero todo eso que digo, que tiene que ver con una exploración estilística, es solamente una parte. Está también la otra, en la que me considero un cronista totalmente clási- 
co. Me interesa ser parte de una tradición que viene de lejos, de Martí, de Rubén Darío, y que deja un documento del mundo que le tocó vivir. Y por eso me sigue entusiasmando este proyecto, en el que llevo 15 años haciendo un registro documental del tiempo que estamos viviendo, del capitalismo en que nos ha tocado trabajar, en el consumismo que hemos tenido que relacionarnos. De cómo hemos inventado nuevas formas de depredar animales para alimentarnos ("La vida de una vaca"), de cómo hemos convertido las ilusiones infantiles en el negocio de moda ("Niños futbolistas"), y ahora, con mi dios y mi religión, mostrar de cómo hemos transformado la espiritualidad en un bien de consumo. Hoy la religión mueve, sólo en Estados Unidos, más dinero que Google y Facebook juntos. Estamos en una época en no es posible separar el consumo de nada. Para el libro entrevisté a empresarios, monjes, filósofos, gurús, ateos, sacerdotes, contadores, mucha gente a la que le preguntaba ¿Se puede comprar un dios? ¿Cómo hago para comprar un dios? Y en las respuestas se ve que no sólo se puede comprar de todo, sino que todo es para comprarlo. Y en ese sentido, desde que comienza a existir la religión portátil, ya comienza a ser parte del mercado, ya empieza a ser parte de un tipo de consumo. Cuando lancé la primera ceremonia de la religión portátil, en la feria del libro de Rosario, las entradas al salón se agotaron un par de días antes. Y muchas veces, que yo hablo del dios que compré, me preguntan cuánto me costó, de qué tamaño es, qué forma tiene, cuánto dura, dónde se puede ver.... Las mismas preguntas que uno hace cuando está interesado en un par de zapatos. En muchas entrevistas, me preguntan qué sería yo con respecto a mi religión y mi dios, ¿un profeta? ¿un papa? Y yo respondo con la verdad: un dueño. Nada más. Soy el dueño. $\mathrm{Y}$ esa propiedad, conseguida con dinero en efectivo, es parte de la herramienta narrativa de esta crónica del consumo. Un autor-dueño contándole una historia de compra y venta a un lector-cliente. Tan simple como eso.

a) En una entrevista recién refiere a que desde que decides comprarte un dios lo más complicado es explicarle a la gente que te quieres comprar uno de verdad, uno real, no en miniatura. ¿Qué se compra cuando se compra un dios? ¿Qué lo llevó a elegir la India como lugar para comprar un dios?

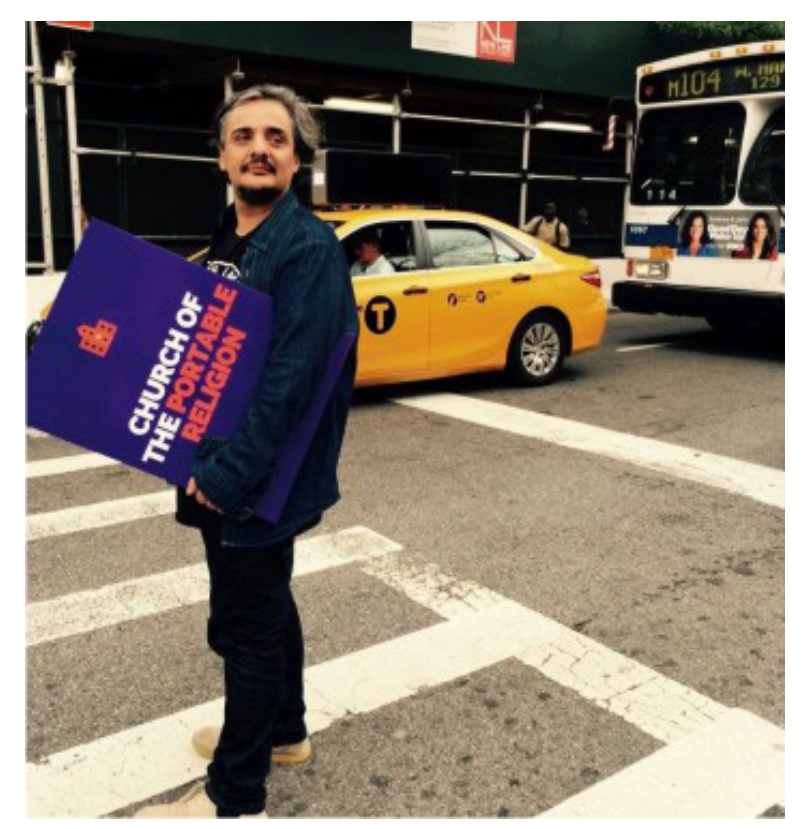

J.P.M: Cuando viajé a la India yo era un ejecutivo de un Grupo de Medios muy tradicional en América Latina. Recorría Chile visitando redacciones de diarios que tenía a cargo, y diseñaba el proyecto para el nuevo diario que íbamos a lanzar. Me pasaba el día en reuniones de presupuestos, me juntaba con ingenieros industriales que proyectaban gráficos en la pared para decirnos, como tarotistas de corbata, cuánto iba a subir o crecer a economía en los próximos tres años y dónde convenía invertir. Almorzaba detrás de un vidrio, para ver qué respondía la gente en un focus-group. Estaba en ese entorno, cuando pido una licencia y viajo a la India, la zona del mundo con más dioses y que se ha convertido para muchos occidentales en una suerte de shopping abierto de la búsqueda espiritual. Me interesaba eso, y arrancar. El plan era simple: recorrer la India para comprar un dios, descubrir ahí que no se podía comprar un dios, volver a mi trabajo y escribir el último libro de la trilogía en mis ratos libres de la oficina. El problema es que sí lo podía comprar. Y lo compré. Y volví a Chile con un dios.

Cuando eres un ejecutivo de Medios y tienes un dios en la bodega del edificio donde vives, no te queda otra cosa que renunciar y seguir este otro proyecto. Y ahí descubres, que cuando te compras un dios, lo que te estás comprando es precisamente eso, un dios. Y claro, al poco tiempo, dejé toda esa vida en una oficina y me embarqué en esta otra que me tiene a cargo de una religión que terminará cuando salga el libro. Ahí terminará "Periodismo Cash", la trilogía del consumo en que vivimos. 
A veces, me preguntan por el lado ético de comprar un dios. Ahí siempre recurro a Kant, para quien la ética tiene mucho que ver con la buena voluntad. Y en mi caso, ir de compras de un ser divino para escribir un libro que muestre una industria no tiene nada moralmente reprochable. Aún así, cada tanto recibo reproches por esta experimentación. La ética es una reflexión permanente sobre la moral, y desde ahí deberíamos analizar la compra de mi dios. Yo creo en esa mirada filosófica de que primero está la sociedad y después tener un dios. La religión, como un invento de la civilización, y no al revés.

4) En una conferencia de prensa de 1974, editada bajo el título "El triunfo de la religión", el psicoanalista francés Jacques Lacan afirma que este triunfo se relaciona con la capacidad de la religión de dar sentido, especialmente a las perturbaciones que introduce la ciencia en la vida de cada uno. Pasaron más de cuarenta años y nos llama la atención que Silicon Valley sea el lugar en el cual hayas diseñado tu religión portátil. Desde ese lugar se está cambiando el mundo mediante el desarrollo científico y tecnológico, sus aplicaciones permiten saber acerca de nuestras ideas políticas, nuestros amigos, lo que comemos y fundamentalmente lo que compramos ¿Por qué elegiste este lugar?

J.P.M: Para Lacan había una sola religión, y esa era la cristiana. Y era más explícito aún, decía que la verdadera religión era la romana. Pasados cuarenta años, uno podría jugar con la idea que hoy la única religión verdadera, la única que funciona sobre todas las otras, es la religión siliconvalliana. Por un lado, ahí se están desarrollando y administrando todas las grandes tecnologías que regulan nuestra vida. Yo vivía en Palo Alto, a menos de 20 cuadras de la casa de Mark Zuckerberg, y cuando andaba en bicicleta pasaba por las oficinas centrales de todas las grandes aplicaciones que están en mi celular. Pero, por otro lado, ahí están almacenados todos nuestros datos, todos los datos del mundo. En Silicon Valley nace el fenómeno de las noticias falsas, las fakenews que vienen a alimentar las expectativas de gente que piensa de determinada manera y quiere leer noticias que apoyen lo que piensen, más que apoyar la verdad. Me pareció era importante diseñar mi iglesia ahí.

Hay escritores que dicen que las historias y los personajes los eligen a ellos. Yo pienso que Silicon Va- lley me eligió a mi. Después de renunciar a mi trabajo postulé a una beca soñada -pero improbable de ganar- en la Universidad de Stanford. Y resulté que me dieron la John S. Knight Journalism Fellow ship, y me mudé al Área de la Bahía en California, con mi dios. Llegué a un lugar donde se está viviendo el futuro, con autos sin chofer que ya se pueden ver, robot estacionando autos, y dónde hay religiones para empleados de Facebook y Google. Cuando le dije al director de Realidad Virtual de Stanford que tenía un dios y que quería explorar la posibilidad de darle un cuerpo con realidad virtual, él se mostró muy entusiasmado. Aparecí en un entorno donde ninguna idea era loca. En las clases de la Escuela de Negocios de Stanford nos pidieron proponer proyectos extremos para el futuro, y yo ahí presenté el diseño del proyecto, a compra del dios, la iglesia y la religión. Los otros alumnos del MBA me empezaron a dar ideas y propuestas, para mejorar el diseño. Por eso nace la iglesia portátil, en Silicon Valley.

5) Entendemos que en la experiencia que estás llevando adelante el dios que compraste en la India sirve de artificio para la escritura periodística. ¿Esta operación o estrategia te ha permitido escribir acerca de aspectos del mundo contemporáneo en los que no hubieras reparado de otro modo? ¿Esta experiencia en particular te permitió descubrir algo nuevo acerca de tu relación a la escritura y al periodismo?

J.P.M: Todo el proyecto del "Periodismo Cash", tiene la idea de mostrar cosas que no conocemos, de los consumos de siempre. Todos estos libros están enfocados en mostrar partes de distintos mercados, que no se suelen iluminar, Por eso es tan importante comprar al protagonista del libro, y tener un autor que asume el papel de autor-dueño todo el tiempo, para llegar a nuevas zonas de las distintas industrias. Y siento que hay lugares que no se pueden llegar de otra manera. Tanto es así, que después de publicar "La vida de una vaca", terminé invitado a exponer a un Encuentro Ganadero muy importante de Rosario, con gente que había vivido y trabajado toda su vida en vacas. Después de publicar "Niños futbolistas", terminé siendo un expositor invitado a un Congreso de la FIFA y de FifPro en Amsterdam. En ambos casos, los que me escuchaban parecían estar frente a temas que les hablaban por primera vez. Y estoy se- 
guro, que haber sido parte de la industria, me ponía en un escenario de interés para ellos.

De ese mismo experimento periodístico viene la compra de mi dios y la Religión Portátil. De la idea de explorar el consumo religioso y de espiritualidad. Pero, es importante destacar que la mayoría de las religiones nacen por razones fuera de las religiosas. Hay religiones que nacen para evadir impuestos, otras que nacen por una apuesta, otras que nacen porque alguien no se puede casar, otras que nacen para invadir. En ese sentido,y pensando en el mundo actual, que una religión nazca de un experimento de periodismo, y me parece normal. Me parece hasta lógico. 